\title{
Cardiovascular disease risk and androgen deprivation therapy in patients with localised prostate cancer: a prospective cohort study
}

Reina Haque ${ }^{*}$, , Marianne UlcickasYood ${ }^{2}$, Xiaoqing Xu ${ }^{1}$, Andrea E Cassidy-Bushrow ${ }^{3}$, Huei-Ting Tsai ${ }^{4}$, Nancy L Keating ${ }^{5,6}$, Stephen K Van Den Eeden ${ }^{7}$ and Arnold L Potosky ${ }^{4}$

${ }^{1}$ Department of Research and Evaluation, Kaiser Permanente Southern California, Pasadena, CA 91101, USA; ${ }^{2}$ Department of Epidemiology, Boston University School of Public Health, Boston, MA 02118, USA; ${ }^{3}$ Henry Ford Health Systems, Detroit, MI 484202, USA; ${ }^{4}$ Lombardi Comprehensive Cancer Center, Georgetown University, Washington, DC 20057, USA; ${ }^{5}$ Division of General Internal Medicine, Brigham and Women's Hospital, Boston, MA 02115, USA; ${ }^{6}$ Department of Health Care Policy, Harvard Medical School, Boston, MA 02115, USA and 'Division of Research, Kaiser Permanente Northern California, Oakland, CA 94612, USA

Background: As androgen deprivation therapy (ADT) is increasingly being used in men with localised prostate cancer, our goal was to examine the association between ADT and the risk of cardiovascular disease (CVD).

Methods: We conducted a prospective cohort study using records of a large health-care system in California. The study included men with newly diagnosed localised prostate cancer (1998-2008) who initially underwent active surveillance $(N=7637)$ and were followed through 2010. We examined 10 individual CVD outcomes. Cox proportional hazard models incorporated time-varying treatment variables and controlled for race/ethnicity, age, and tumour characteristics, recurrence risk, CVD medication use, and CVD risk factors.

Results: Of the 7637 subjects, nearly $30 \%$ were exposed to ADT. In the multivariable analyses, ADT was associated with an increased risk of heart failure (adjusted $H R=1.81,95 \% \mathrm{Cl} 1.40-2.32$ ) in men without preexisting CVD. Elevated risks of arrhythmia (adjusted $\mathrm{HR}=1.44,95 \% \mathrm{Cl} 1.02-2.01$ ), and conduction disorder (adjusted $\mathrm{HR}=3.11,95 \% \mathrm{Cl} 1.22,7.91$ ) were only observed among patients with preexisting CVD.

Conclusions: In men with clinically localised prostate cancer who were initially under active surveillance, ADT was associated with a greater risk of heart failure in men without any preexisting CVD. We also found an increased risk of arrhythmia and conduction disorder in men with preexisting CVD. This study provides the basis for identifying high-risk men treated with ADT who might benefit from regular cardiac monitoring and lifestyle modification recommendations.

Androgen deprivation therapy (ADT), a hormone treatment, is recommended for advanced prostate cancer but is increasingly being used for localised prostate cancer treatment (Sharifi et al, 2005). In parallel, localised prostate cancer diagnosis has tremendously increased, reaching $90 \%$ in the United States, given the widespread prostate screening antigen
(PSA) testing (Thompson et al, 2007). ADT lowers male hormone to castration testosterone levels within 3 weeks after treatment (Burton et al, 2013). Several randomised clinical trials suggest that radiation therapy plus ADT improves overall survival among patients with locally advanced disease (i.e., extracapsular or node positive) $v s$ radiation therapy alone, but

${ }^{\star}$ Correspondence: Dr R Haque; E-mail: Reina.Haque@kp.org

Received 14 March 2017; revised 6 July 2017; accepted 24 July 2017; published online 24 August 2017

(C) 2017 Cancer Research UK. All rights reserved 0007-0920/17 
findings remain controversial (Bolla et al, 1997, 2002, 2009; Horwitz et al, 2008).

Despite certain benefits of ADT, it is associated with problematic side effects similar to those experiencing testosterone deficiency due to other causes, such as gynaecomastasia and erectile dysfunction (Sharifi et al, 2005; Cattabiani et al, 2012; Nguyen et al, 2015). Additionally, androgen deficiency has been linked to cardiovascular disease (CVD) risk factors. For example, low bioavailable testosterone may increase atherosclerosis risk (Hak et al, 2002; Jones et al, 2005; Khaw et al, 2007). However, these studies mainly included much older men.

Conflicting evidence exists regarding the association between ADT and CVD, and prior studies have not been able to sufficiently adjust for a comprehensive set of confounders (Bolla et al, 2002; Keating et al, 2006; D'Amico et al, 2007; Van Hemelrijck et al, 2010; Nguyen et al, 2011; O'Farrell et al, 2015). A meta-analysis of observational studies found a $40 \%$ increased risk of non-fatal CVD in men with prostate cancer who used ADT, specifically gonadotropin-releasing hormone $(\mathrm{GnRH})$ agonists (Bosco et al, 2015). By contrast, ADT was not associated with CVD mortality in an earlier report (Punnen et al, 2011). The cardiotoxicity of ADT was confirmed in a population-based study suggesting a slightly elevated myocardial infarction risk regardless of existing CVD history (Keating et al, 2013), though other studies suggested that CVD-specific and all-cause mortality only occurred in patients with preexisting CVD (Nanda et al, 2014; Ziehr et al, 2015). Thus, given the mixed cohorts of both patients with and without existing CVD, distinguishing whether ADT is associated the development of CVD or accelerating the progression of the existing disease remains unclear. Although studies based on both SEERMedicare and VA databases found moderate associations between ADT and non-fatal CVD events, they did not have access to a broad set of covariates, such as CVD medications, which are commonly used by men with localised prostate cancer (Keating et al, 2006, 2010).

Given this background, our goal was to assess the association of ADT and important incident CVD outcomes in a cohort that also included younger men with localised prostate cancer initially conservatively managed. We accounted for important confounders, including prior CVD history, PSA levels, CVD medications, and CVD risk factors. Additionally, we assessed whether ADT only has effect on new-onset CVD or also on the progression of preexisting cardiovascular conditions. To our knowledge, this is the first study to comprehensively account for CVD medications, including antiarrhythmic medications, anticoagulants, antihypertensive medications, calcium channel blockers, digoxin, nitrates, and antidiabetics.

\section{MATERIALS AND METHODS}

Study design and setting. We conducted a prospective cohort study of men with newly diagnosed localised prostate cancer using electronic health records from Kaiser Permanente Southern California (KPSC) health-care delivery system. KPSC includes a network of 6600 physicians who serve 14 hospitals, over 220 outpatient clinics, and nearly 4.3 million members. The health plan's database includes comprehensive information from prospectively recorded inpatient and outpatient diagnoses, clinical encounters, laboratory test values, pharmacy data and cancer registry data.

Participants. We identified 30092 men diagnosed with prostate cancer between 1998 and 2008 from the health plan's NCI SEERaffiliated tumour registry (Potosky et al, 2014). Men were excluded if they had advanced stage prostate cancer at diagnosis (T4/nodal involvement/distant metastasis, $N=3352$ ); received other therapies, including radiation, radical prostatectomy, or chemotherapy, within 1 year after prostate cancer diagnosis $(N=18904)$; underwent orchiectomy within 1 year after diagnosis $(N=59)$; received neoadjuvant $\mathrm{ADT}(N=120)$; or were missing date of death and other data errors $(N=16)$. Four men who died on the cohort entry date were further excluded from the study, resulting in a final cohort of 7637 men with clinically localised prostate cancer who initially were under active surveillance.

Androgen deprivation therapy. The main independent variable was exposure to any ADT after prostate cancer diagnosis. ADT was ascertained from electronic pharmacy dispensing records and outpatient procedures. This included men who might have received $\mathrm{ADT}$ as their sole primary therapy for clinically localised disease or as salvage therapy anytime thereafter. ADT was defined as a GnRH analogist (leuprolide, goserelin, or triporelin) with or without an oral antiandrogen (flutamide, bicalutamide, or nilutamide for combined androgen blockade). ADT was treated as dichotomous (ever/never) time-dependent variable. During the study period, ADT antagonists (abarelix and degarelix) were not available in the KPSC formulary. Men contributed information to the exposed group only after the drug initiation and were categorised as exposed to ADT once initiated until reaching one of the study's end points.

Study outcomes. The cohort was followed through death or 31 December 2010 for the study endpoints. We identified first occurrence of CVD outcomes based on hospitalisation with a primary diagnoses of a CVD event (using ICD9 and ICD10 discharge diagnosis codes; see Supplementary Appendix 1). We focussed on CVD outcomes that were serious enough to require hospitalisation using a previously published algorithm with demonstrated validity of diagnosis codes in the electronic health records (Haque et al, 2011). Men with multiple primary CVD diagnoses on the same date were assigned to one outcome group according to this algorithm: (1) acute myocardial infarction, (2) cardiac arrest, (3) stroke, (4) heart failure (HF), (5) hypertensive heart disease with HF, (6) cardiomyopathy, (7) arrhythmias; (8) valvuopathy, (9) angina pectoris; and (10) conduction disorder. Furthermore, we combined the individual events and grouped them into three major categories based on the mechanism of disease: cardiac ischaemia, stroke, and other heart disease (Haque et al, 2011). The CVD outcomes were treated as a binary variable. Information on the date of death for health plan members were derived from a combination of clinical databases, linkages with California death certificate records, and linkage with the national Social Security Administration data. There were 178 patients who died owing to CVD but with no specified CVD diagnoses during their health plan membership. We handled such patients in two ways. First, patients were combined with those who died owing to any other causes and were censored at the death date. Second, we excluded the 178 men in sensitivity analysis and compared the HR results with those of the full cohort.

Covariates. Because ADT users and non-users could have been systematically different in prognostic factors of prostate cancer that may also affect the risk of CVD, we compared tumour characteristics (year of diagnosis, Gleason score, prostate cancer risk group, baseline PSA level) between the two groups and adjusted those factors in the multivariable analyses. In addition, we extracted other covariates, including patients' demographics (age, race/ethnicity), prior history of $\mathrm{CVD}$, risk factors for CVD (hypertension, diabetes), Charlson comorbidity score, and CVD medications. The CVD medications included antiarrthymics, anticoagulants, antilipemics, calcium channel blockers, digoxin/ lanoxin, nitrates, and antidiabetic drugs. As the antihypertensive medication use did not differ by exposure status, we excluded it 
from the covariate set. The demographic information and tumour characteristics were gathered from electronic health records around the prostate cancer diagnosis date while CVD risk factors and comorbidity scores were captured 1 year before diagnosis. CVD medications were extracted from pharmacy dispensing and coded as time-dependent variables. History of preexisting CVD conditions (at least two records) were ascertained from inpatient and outpatient electronic health records up to 2 years before prostate cancer diagnosis. Men must have had at least two consecutive prescriptions within 90 days during the followup period to be counted as exposed to a particular CVD medication.

Statistical analyses. Differences in demographic characteristics, tumour status, CVD risk factors, and medications were first examined by comparing frequency distributions by ADT use status. Because subjects had varying lengths of follow-up, we examined the person-year rates of each of the CVD outcomes. To estimate the associations between ADT and each of the 10 cardiovascular outcomes, we fit 10 separate time-dependent Coxproportional hazards models. For each model, the follow-up years began on prostate cancer diagnosis date and ended on the date of the incident CVD as the outcome event or censoring event corresponding to termination of health plan membership, death, or end of the study period (31 December 2010), whichever occurred first. In the Cox models, ADT and the prescription medications were treated as time-dependent variables (i.e., 0 up to start date; 1 after drug initiation). The multivariable Cox proportional hazards models were adjusted for all potential confounders deemed to be clinically or statistically significant $(P<0.05)$. These confounders included demographics, tumour characteristics (stage at prostate cancer diagnosis, Gleason score, risk group), and CVD medications. In sensitivity analyses, we further adjusted for BMI and smoking. The proportional hazards assumption was tested via graphic plots and Schoenfeld residuals. Because a proportion of cases were missing at least one or more of the key clinical prognostic variables (clinical stage, Gleason score, or baseline PSA), we performed multiple imputations using all other covariates. We constructed five imputed data sets, each having estimates for the missing values for PSA, Gleason score, and T-stage. We then pooled the estimates and corresponding s.e. across the five imputations using Rubin's method (Rubin, 2008). All model results used these imputed data sets; multivariable models using only the complete cases did not show any significant deviations from the results presented here. To distinguish the effect on newly diagnosed CVD from the effect on the progression on preexisting CVDs, we also conducted a sensitivity analysis to assess whether preexisting CVD was an important confounder by performing analyses stratified by the presence or absence of preexisting CVD. In another sensitivity analysis, we repeated the Cox model excluding the men who died of CVD without having a prior CVD diagnosis $(N=178)$. Because these outcomes were studied in prior reports, we decided not to make adjustments in the $P$-values for multiple comparisons per Rothman (1990). All statistical analyses were conducted using SAS (Version 9.4, SAS institute Inc., Cary, NC, USA).

\section{RESULTS}

Of the 7637 men with localised prostate cancer who did not undergo curative intent therapy (initially conservatively managed), nearly $30 \%(n=2170)$ were exposed to ADT during a median of 3.4 years of follow-up (interquartile range: 1.6-6.0 years). The cohort includes both men with $(N=1665,22 \%)$ and without $(N=5972,78 \%)$ preexisting CVD. Of the 2170 exposed to ADT, 36\% began treatment within 6 months after prostate cancer diagnosis, 32\% between 6-24 months, and 32\% after 2 years. Thus ADT might have been prescribed as primary or salvage therapy. There were 2061 men who experienced CVD events over 31255 person-years, which translated to 65.9 event per 1000 PY. The average time to a CVD event was 3.2 years (s.d. 2.6 years). The ADT group had significantly longer follow-up compared with the non-user group (average of $3.6 v s 5.3$ years).

Comparison of patients by ADT status. Demographics, comorbidities, CVD risk factors, and tumour characteristics are displayed in Table 1 by ADT status. The ADT group was more likely to be older, have hypertension, diabetes, and more comorbid conditions 1 year before prostate cancer diagnoses. Prevalence of preexisting CVD was $22.5 \%$ among men who used ADT and $21.5 \%$ among non-users. ADT use was strongly associated with patients' tumour characteristics. Compared with the ADT group, a larger proportion of the non-user group was diagnosed after 2006 (31.9 vs 20.5\%), had lower Gleason scores (69.0 vs $42.3 \%$ for Gleason score $<7$ ), at less advanced tumour stage (69.1 vs $55.8 \%$ for T1), and were in the lower-risk group (47.7 vs $19.2 \%$ for low risk). In the ADT group, a larger proportion of patients had higher baseline PSA level (17.3 vs $36.1 \%$ for PSA $>10$ units).

Use of CVD and antidiabetic medications by ADT status. Table 2 shows patients' CVD medication use by ADT use. Significantly more patients in the ADT group used anticoagulants, antilipemics, calcium channel blockers, digoxin/lanoxin, nitrates, and antidiabetic drugs than patients in the non-user group. Thus ADT users were more likely to be treated for CVD.

CVD occurrence by ADT status. The person-year incidence rates, adjusted HRs and 95\% CIs of each CVD event, and HRs stratified by history of preexisting CVD are shown in Table 3 and Figure 1. Generally, the unadjusted person-year absolute CVD rates were higher for men treated with ADT than for non-users. The crude CVD rates were higher among men with more advanced age at cancer diagnosis and with worse tumour characteristics, that is, higher T-stage, Gleason score, and recurrence risk group (Supplementary Appendix 2). After adjusting for all other covariates including CVD medications in the multivariate models, men exposed to ADT were $27 \%$ more likely to develop HF than non-exposed men (adjusted $\mathrm{HR}=1.27,95 \% \mathrm{CI}$ : $1.06-1.51$ ); this association was seen in men without preexisting CVD (adjusted $\mathrm{HR}=1.81,95 \% \mathrm{CI}: 1.40-2.32)$ but not in men with preexisting CVD (adjusted $\mathrm{HR}=1.00,95 \% \mathrm{CI}=0.78-1.29$ ). ADT users with preexisting CVD were at increased risk of developing arrhythmia (adjusted HR $=1.44,95 \% \mathrm{CI}: 1.02-2.01$ ) and conduction disorders (adjusted HR $=3.11$, 95\% CI: 1.22-7.91; Figure 1). We did not find increased risks for ischaemic heart disease, stroke, or the other conditions. To assess the potential confounding effect of BMI and smoking, we performed a sensitivity analysis comparing models with and without additional adjustment for these factors in a subset of the cohort $(N=1983)$ with complete information of the two lifestyle factors; there was little change in the hazard ratios for the three major CVD groups (Table 4). After multiple imputations for missing data (PSA level: $(N=1270,15.8 \%)$, Gleason score: $(N=709,9.3 \%)$, and T-stage $(N=96,1.3 \%)$, the HR results did not substantially change. In the sensitivity analysis, excluding those 178 patients who died of CVD, the HRs were approximately the same as in the full cohort (data not shown). In stratified analysis among African-American patients (data not shown), the magnitude of association was greater in arrhythmia $(\mathrm{HR}=1.46,95 \% \mathrm{CI}: 0.87-2.45)$ and $\mathrm{HF}(\mathrm{HR}=1.65$, 95\% CI: 1.09-2.50). We also found increased risks in angina $(\mathrm{HR}=4.37,95 \% \mathrm{CI}: 0.99-13.36)$ and cardiomyopathy $(\mathrm{HR}=7.86$, 95\% CI: $1.22-50.62$ ) in African-American men, although confidence intervals were wide. 
Table 1. Demographic and tumour characteristics of prostate cancer patients at baseline by ADT exposure

\begin{tabular}{|c|c|c|c|c|}
\hline & $\begin{array}{c}\text { ADT not } \\
\text { used } \\
(N=5467)\end{array}$ & $\begin{array}{l}\text { ADT used } \\
(N=2170)\end{array}$ & $\begin{array}{c}\text { Total } \\
(N=7637)\end{array}$ & $P$-value \\
\hline \multicolumn{5}{|l|}{ Age, years } \\
\hline $\begin{array}{l}\leqslant 65 \\
>65\end{array}$ & $\begin{array}{l}2072(37.9) \\
3395(62.1)\end{array}$ & $\begin{array}{r}430(19.8) \\
1740(80.2)\end{array}$ & $\begin{array}{l}2502(32.8) \\
5135(67.2)\end{array}$ & $<0.0001$ \\
\hline \multicolumn{5}{|c|}{ Charlson score 1 year before PC diagnoses } \\
\hline $\begin{array}{l}0 \\
1-2 \\
3+ \\
\text { Missing }\end{array}$ & $\begin{array}{c}2716(60.3) \\
1426(31.7) \\
361(8.0) \\
964\end{array}$ & $\begin{array}{c}826(52.7) \\
584(37.3) \\
157(10.0) \\
603\end{array}$ & $\begin{array}{c}3542(58.4) \\
2010(33.1) \\
518(8.5) \\
1567\end{array}$ & $<0.0001$ \\
\hline \multicolumn{5}{|c|}{ Race/ethnicity } \\
\hline $\begin{array}{l}\text { Hispanic } \\
\text { White } \\
\text { African- } \\
\text { American } \\
\text { Asian }\end{array}$ & $\begin{array}{r}793(14.5) \\
3356(61.4) \\
856(15.7)\end{array}$ & $\begin{array}{r}312(14.4) \\
1292(59.5) \\
405(18.7) \\
\\
161(7.4)\end{array}$ & $\begin{array}{c}1105(14.5) \\
4648(60.9) \\
1261(16.5) \\
623(8.2)\end{array}$ & 0.0097 \\
\hline \multicolumn{5}{|c|}{ Hypertension } \\
\hline $\begin{array}{l}\text { No } \\
\text { Yes }\end{array}$ & $\begin{array}{l}2237(40.9) \\
3230(59.1)\end{array}$ & $\begin{array}{r}789(36.4) \\
1381(63.6)\end{array}$ & $\begin{array}{l}3026(39.6) \\
4611(60.4)\end{array}$ & 0.0002 \\
\hline \multicolumn{5}{|l|}{ Diabetes } \\
\hline $\begin{array}{l}\text { No } \\
\text { Yes }\end{array}$ & $\begin{array}{r}4572(83.6) \\
895(16.4)\end{array}$ & $\begin{array}{r}1729(79.7) \\
441(20.3)\end{array}$ & $\begin{array}{l}6301(82.5) \\
1336(17.5)\end{array}$ & $<0.0001$ \\
\hline \multicolumn{5}{|c|}{ Year of PC diagnosis } \\
\hline $\begin{array}{l}1998-2000 \\
2001-2005 \\
2006+\end{array}$ & $\begin{array}{l}1256(23.0) \\
2465(45.1) \\
1746(31.9)\end{array}$ & $\begin{array}{l}826(38.1) \\
899(41.4) \\
445(20.5)\end{array}$ & $\begin{array}{l}2082(27.3) \\
3364(44.0) \\
2191(28.7)\end{array}$ & $<0.0001$ \\
\hline \multicolumn{5}{|c|}{ Stage at diagnosis } \\
\hline $\begin{array}{l}\text { T1 } \\
\text { T2 } \\
\text { T3 } \\
\text { Missing }\end{array}$ & $\begin{array}{c}3726(69.1) \\
1600(29.7) \\
69(1.3) \\
72\end{array}$ & $\begin{array}{c}1196(55.8) \\
837(39.0) \\
112(5.2) \\
25\end{array}$ & $\begin{array}{c}4922(65.3) \\
2437(32.3) \\
181(2.4) \\
97\end{array}$ & $<0.0001$ \\
\hline \multicolumn{5}{|c|}{ Gleason score } \\
\hline $\begin{array}{l}<7 \\
7 \\
>7 \\
\text { Missing }\end{array}$ & $\begin{array}{c}3388(69.0) \\
1088(22.1) \\
437(8.9) \\
554\end{array}$ & $\begin{array}{c}851(42.3) \\
631(31.4) \\
528(26.3) \\
160\end{array}$ & $\begin{array}{c}4239(61.2) \\
1719(24.8) \\
965(13.9) \\
714\end{array}$ & $<0.0001$ \\
\hline \multicolumn{5}{|l|}{ Risk groups } \\
\hline $\begin{array}{l}\text { Low } \\
\text { Intermediate } \\
\text { High } \\
\text { Missing }\end{array}$ & $\begin{array}{c}2218(47.7) \\
1398(30.1) \\
1030(22.2) \\
821\end{array}$ & $\begin{array}{c}389(19.2) \\
637(31.5) \\
997(49.3) \\
147\end{array}$ & $\begin{array}{c}2607(39.1) \\
2035(30.5) \\
2027(30.4) \\
968\end{array}$ & $<0.0001$ \\
\hline \multicolumn{5}{|c|}{ Preexisting CVD } \\
\hline $\begin{array}{l}\text { No } \\
\text { Yes }\end{array}$ & $\begin{array}{l}4290(78.5) \\
1177(21.5)\end{array}$ & $\begin{array}{r}1682(77.5) \\
488(22.5)\end{array}$ & $\begin{array}{l}5972(78.2) \\
1665(21.8)\end{array}$ & 0.3598 \\
\hline \multicolumn{5}{|c|}{ Smoking status ${ }^{a}$} \\
\hline $\begin{array}{l}\text { Current } \\
\text { Former } \\
\text { Never } \\
\text { Missing }\end{array}$ & $\begin{array}{r}451(12.8) \\
1472(41.7) \\
1611(45.6) \\
1933\end{array}$ & $\begin{array}{c}190(12.9) \\
680(46.1) \\
605(41.0) \\
695\end{array}$ & $\begin{array}{c}641(12.8) \\
2152(43.0) \\
2216(44.2) \\
2628\end{array}$ & 0.0078 \\
\hline \multicolumn{5}{|l|}{$\mathrm{BMI}^{\mathrm{b}}$} \\
\hline $\begin{array}{l}\text { Underweight } \\
\text { or normal } \\
\text { Overweight } \\
\text { Obese }\end{array}$ & $\begin{array}{l}729(43.9) \\
435(26.2)\end{array}$ & $\begin{array}{l}181(40.0) \\
100(22.1)\end{array}$ & $\begin{array}{l}910(43.0) \\
535(25.3)\end{array}$ & 0.0098 \\
\hline $\begin{array}{l}\text { Abbreviations: } \\
\text { cardiovascular d } \\
\text { two-sided. } \\
a_{35 \%} \text { was missin } \\
b_{72} \% \text { missing, B }\end{array}$ & $\begin{array}{l}\text { androgen dep } \\
P C=\text { prostate } \\
\text { oking history wa } \\
\text { s not available }\end{array}$ & $\begin{array}{l}\text { ion therapy; } \\
\text { cer. P-value bas } \\
\text { th available in } \\
\text { MR until } 2006 \text {. }\end{array}$ & $\begin{array}{l}=\text { body mass } \\
\text { on Pearson's c } \\
\text { until } 2004 \text {. }\end{array}$ & $\begin{array}{l}\text { ndex; } C V D= \\
\text { ii-square test }\end{array}$ \\
\hline
\end{tabular}

\section{DISCUSSION}

In this prospective population-based study of insured men with localised prostate cancer who were initially conservatively managed
Table 2. Simultaneous medications related with CVD by ADT exposure

\begin{tabular}{|c|c|c|c|c|}
\hline & $\begin{array}{l}\text { ADT not used } \\
(N=5467)\end{array}$ & $\begin{array}{l}\text { ADT used } \\
(N=2170)\end{array}$ & $\begin{array}{c}\text { Total } \\
(N=7637)\end{array}$ & $P$-value \\
\hline \multicolumn{5}{|c|}{ Antiarrthymics } \\
\hline No & $5457(99.8)$ & $2162(99.6)$ & 7619 (99.8) & 0.1311 \\
\hline$Y_{e s}{ }^{a}$ & $10(0.2)$ & $8(0.4)$ & $18(0.2)$ & \\
\hline \multicolumn{5}{|c|}{ Anticoagulants } \\
\hline No & $5182(94.8)$ & 1978 (91.2) & 7160 (93.8) & $<0.0001$ \\
\hline$Y_{e s}{ }^{a}$ & $285(5.2)$ & $192(8.8)$ & 477 (6.2) & \\
\hline \multicolumn{5}{|c|}{ Antihypertensives } \\
\hline No & 5201 (95.1) & 2064 (95.1) & 7265 (95.1) & 0.9719 \\
\hline Yes $^{a}$ & $266(4.9)$ & $106(4.9)$ & $372(4.9)$ & \\
\hline \multicolumn{5}{|c|}{ Antilipemics } \\
\hline No & $3653(66.8)$ & 1187 (54.7) & 4840 (63.4) & $<0.0001$ \\
\hline Yes $^{a}$ & 1814 (33.2) & $983(45.3)$ & 2797 (36.6) & \\
\hline \multicolumn{5}{|c|}{ Calcium channel blockers } \\
\hline No & $5004(91.5)$ & $1902(87.6)$ & $6906(90.4)$ & $<0.0001$ \\
\hline Yes $^{a}$ & $463(8.5)$ & 268 (12.4) & 731 (9.6) & \\
\hline \multicolumn{5}{|c|}{ Antidiabetic drugs } \\
\hline No & 5090 (93.1) & $1928(88.8)$ & 7018 (91.9) & $<0.0001$ \\
\hline$Y_{e s}{ }^{a}$ & 377 (6.9) & 242 (11.2) & $619(8.1)$ & \\
\hline \multicolumn{5}{|c|}{ Digoxin/lanoxin } \\
\hline No & 5364 (98.1) & 2092 (96.4) & 7456 (97.6) & $<0.0001$ \\
\hline$Y_{e s}{ }^{a}$ & $103(1.9)$ & $78(3.6)$ & $181(2.4)$ & \\
\hline \multicolumn{5}{|c|}{ Nitrates } \\
\hline No & $5232(95.7)$ & $1982(91.3)$ & $7214(94.5)$ & $<0.0001$ \\
\hline$Y_{e s}{ }^{a}$ & $235(4.3)$ & $188(8.7)$ & $423(5.5)$ & \\
\hline
\end{tabular}

and followed a maximum of 13 years, we found associations between ADT and certain CVD outcomes after adjustment for multiple confounder variables, including hypertension, diabetes, age and stage of prostate cancer diagnosis, Gleason score, prostate cancer risk score, race/ethnicity, and covariate CVD medications. The increased risk of other heart diseases (e.g., arrhythmia, HF, and conduction disorder) among ADT users persisted even in the sensitivity analysis that controlled for BMI and smoking. ADT use was associated with an increased risk of HF; this finding was similar to a study in UK General Practice Research Database but they observed a slightly smaller effect size (Martin-Merino et al, 2011). ADT was also associated with arrhythmia and conduction disorders but only among men with preexisting CVD. A major advantage of our study was that we were able to consider the influence of cardiovascular medications and examine a comprehensive set of outcomes.

Given the pharmacological functions of ADT, our findings may be explained by possible mechanisms pertaining to testosterone deficiency and CVD risk factors. For example, testosterone deficiency increases fat mass, a risk factor of CVDs, such as HF and arrhythmia. Men with androgen deficiency also have abnormal lipid profiles, elevated pro-inflammatory factors, endothelial function, and hypertension (Traish et al, 2009). In the Caperhilly Study, Smith et al (2005) suggested that the cortisol/testosterone ratio was related with ischaemic heart disease, mediated through insulin resistance, which may exacerbate conduction disorders (Traish et al, 2009; Keating et al, 2010). Therefore, the negative impact of testosterone deficiency may derive from its influencing CVD risk factors. The observed increased risk of arrhythmia among ADT users in our study is consistent with the confirmed inverse association between testosterone level and prolonged QT interval, a strong risk factor of fatal arrhythmias (van Noord et al, 
Table 3. Crude disease rates and hazard ratios of incident CVD outcomes

\begin{tabular}{|c|c|c|c|c|c|c|c|c|c|c|c|c|}
\hline \multirow[b]{2}{*}{ CVD } & \multicolumn{2}{|c|}{ Total, PY: 31255} & \multicolumn{2}{|c|}{ ADT used, PY: 7527} & \multicolumn{2}{|c|}{$\begin{array}{l}\text { ADT not used, } \\
\text { PY: } 23728\end{array}$} & \multicolumn{2}{|c|}{$\begin{array}{l}\text { All patients } \\
(n=7637)\end{array}$} & \multicolumn{2}{|c|}{$\begin{array}{l}\text { Patients without } \\
\text { preexisting CVD } \\
\quad(n=5972)\end{array}$} & \multicolumn{2}{|c|}{$\begin{array}{l}\text { Patients with } \\
\text { preexisting CVD } \\
\quad(n=1665)\end{array}$} \\
\hline & $N$ & $\begin{array}{l}\text { Crude } \\
\text { rate }^{a}\end{array}$ & $N$ & Crude rate & $N$ & Crude rate & $\begin{array}{l}\text { Adjusted } \\
\text { HR }\end{array}$ & $95 \% \mathrm{Cl}$ & $\begin{array}{c}\text { Adjusted } \\
\text { HR }\end{array}$ & $95 \% \mathrm{Cl}$ & $\begin{array}{c}\text { Adjusted } \\
\text { HR }\end{array}$ & $95 \% \mathrm{Cl}$ \\
\hline \multicolumn{13}{|l|}{ Cardiac ischaemia } \\
\hline AMI & 431 & 13.79 & 139 & 18.47 & 292 & 12.31 & 1.19 & $0.95,1.49$ & 1.24 & $0.93,1.64$ & 1.14 & $0.78,1.65$ \\
\hline Angina & 61 & 1.95 & 18 & 2.39 & 43 & 1.81 & 0.95 & $0.52,1.75$ & 0.64 & $0.24,1.67$ & 1.31 & $0.58,2.93$ \\
\hline Cardiac arrest & 58 & 1.86 & 19 & 2.52 & 39 & 1.64 & 1.15 & $0.62,2.12$ & 1.29 & $0.61,2.76$ & 0.85 & $0.25,2.83$ \\
\hline Total & 550 & 17.68 & 176 & 23.38 & 374 & 15.76 & 1.15 & $0.95,1.41$ & 1.18 & $0.91,1.52$ & 1.13 & $0.82,1.57$ \\
\hline \multicolumn{13}{|l|}{ Stroke } \\
\hline Total & 71 & 2.27 & 23 & 3.06 & 48 & 2.02 & 1.09 & $0.63,1.88$ & 0.93 & $0.46,1.88$ & 1.62 & $0.64,4.12$ \\
\hline \multicolumn{13}{|l|}{ Other heart diseases } \\
\hline Arrhythmia & 564 & 18.05 & 176 & 23.38 & 388 & 16.35 & 1.17 & $0.96,1.43$ & 1.07 & $0.84,1.37$ & 1.44 & $1.02,2.01$ \\
\hline Heart failure & 689 & 22.04 & 244 & 32.42 & 445 & 18.75 & 1.27 & $1.06,1.51$ & 1.81 & $1.40,2.32$ & 1.00 & $0.78,1.29$ \\
\hline Cardmyopathy & 36 & 1.15 & 16 & 2.13 & 20 & 0.84 & 1.84 & $0.87,3.88$ & 2.25 & $0.74,6.78$ & 1.51 & $0.51,4.46$ \\
\hline Conduction disorder & 81 & 2.59 & 27 & 3.59 & 54 & 2.28 & 1.40 & $0.84,2.35$ & 1.08 & $0.57,2.03$ & 3.11 & $1.22,7.91$ \\
\hline Hypertensive heart disease & 3 & 0.1 & 1 & 0.13 & 2 & 0.08 & NA & NA & NA & NA & NA & NA \\
\hline Valvuopathy & 67 & 2.14 & 22 & 2.92 & 45 & 1.90 & 1.22 & $0.69,2.17$ & 1.08 & $0.53,2.21$ & 1.59 & $0.59,4.26$ \\
\hline Total & 1440 & 45.64 & 486 & 64.56 & 954 & 40.21 & 1.25 & $1.11,1.42$ & 1.34 & $1.14,1.58$ & 1.22 & $1.01,1.47$ \\
\hline \multicolumn{13}{|c|}{ 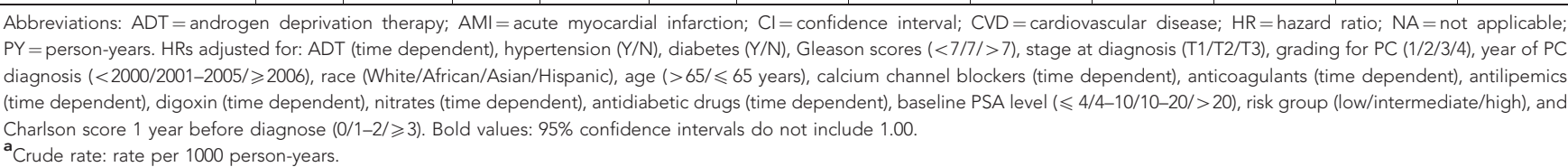 } \\
\hline
\end{tabular}

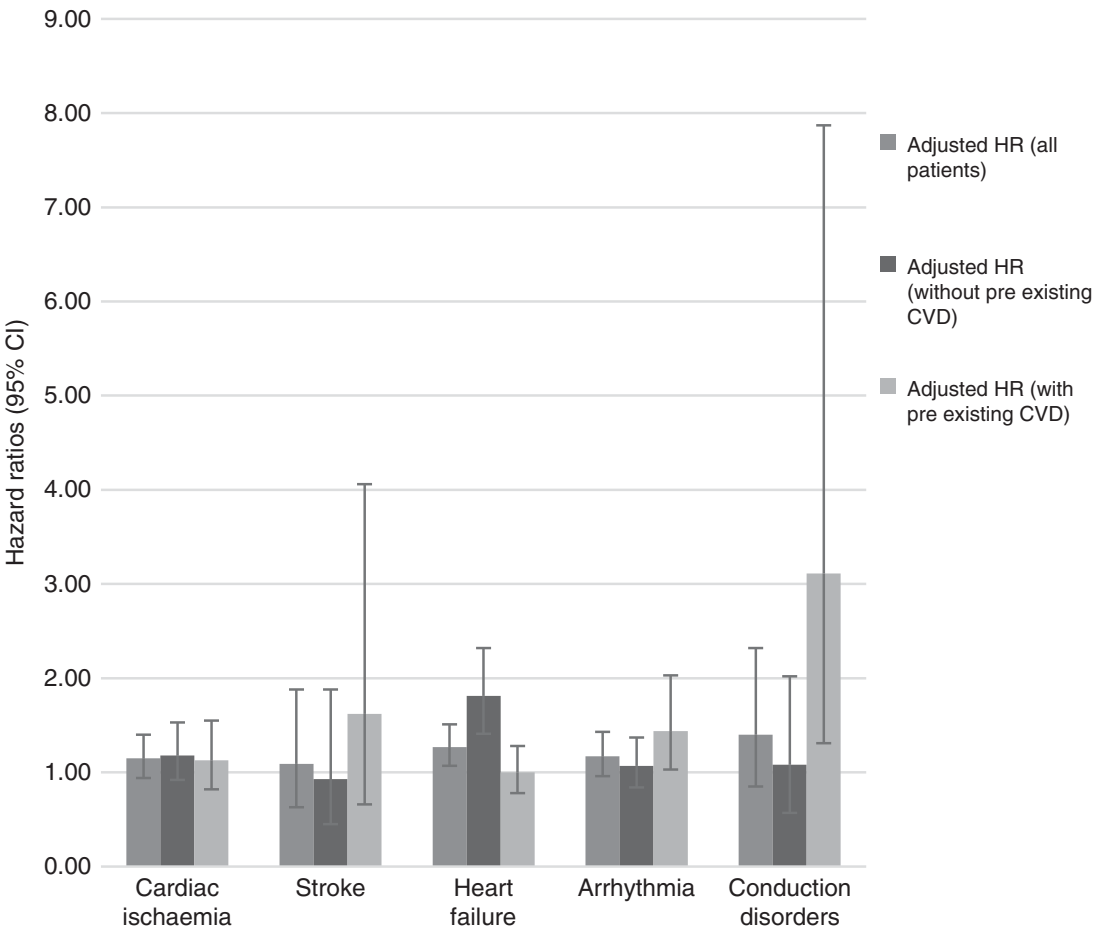

Figure 1. Adjusted HRs of CVD events following ADT exposures.

2011; Lubart et al, 2015). We also found an increased risk of conduction disorder among patients with preexisting CVD $(\mathrm{HR}=3.11,95 \% \mathrm{CI}: 1.22-7.91)$ but not in those without CVD history $(\mathrm{HR}=1.08,95 \% \mathrm{CI}: 0.57,2.03)$. Reasons for this are not clear, but it is possible that those with preexisting CVD may be more susceptible to developing conduction disorders or that individuals with certain preexisting conditions are more likely to have greater health-care utilisation, be monitored more frequently, and hence, more likely to be diagnosed with other CVD conditions. This observation requires additional confirmation.

The adjusted hazard ratios of ischaemic heart disease and stroke were $>1.00$ (1.15 and 1.09) but not significantly different between the ADT use and non-use. The lack of elevated risks in our study may be attributed to higher proportion of younger men in our study compared with the rates in a SEER-Medicare study (33\% of men in our cohort were aged $\leqslant 65$ years; Keating et al, 2006), the 
Table 4. Hazard ratio estimates of incident CVD outcomes from different models $(N=1983)$

\begin{tabular}{|c|c|c|c|c|c|c|}
\hline \multirow[b]{2}{*}{ CVD } & \multicolumn{2}{|c|}{ Multivariable models ${ }^{a}$} & \multicolumn{2}{|c|}{ Additional adjustment for smoking } & \multicolumn{2}{|c|}{$\begin{array}{l}\text { Additional adjustment for } \\
\qquad \mathrm{BMI}+\text { smoking }\end{array}$} \\
\hline & Adjusted HR & $95 \% \mathrm{Cl}$ & Adjusted HR & $95 \% \mathrm{Cl}$ & Adjusted HR & $95 \% \mathrm{Cl}$ \\
\hline Cardiac ischaemiab $^{\mathbf{b}}$ & 1.15 & $0.94,1.40$ & 1.14 & $0.93,1.39$ & 1.12 & $0.92,1.37$ \\
\hline Stroke & 1.04 & $0.60,1.80$ & 1.01 & $0.58,1.76$ & 1.01 & $0.58,1.76$ \\
\hline Other heart diseases $^{c}$ & 1.24 & $1.10,1.40$ & 1.24 & $1.10,1.40$ & 1.23 & $1.09,1.39$ \\
\hline \multicolumn{7}{|c|}{ 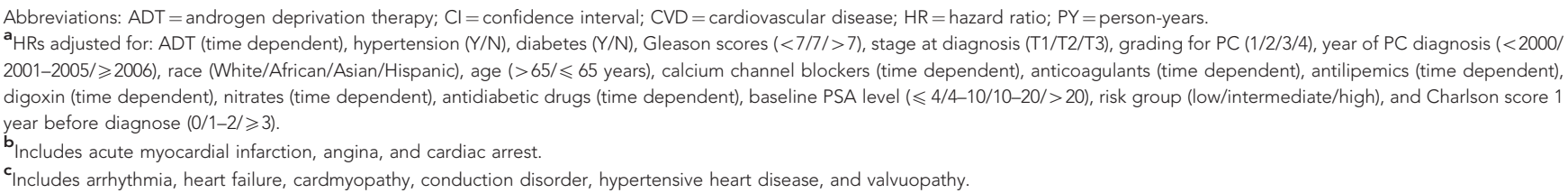 } \\
\hline
\end{tabular}

health plan's management of CVD risk factors, and our ascertainment of outcomes from inpatient databases only (i.e., those conditions that were serious enough to require hospitalisation). Importantly, we were able to ascertain oral antiandrogen use, thereby minimising exposure misclassification. If we had also included patients who died of CVD as part of the outcome (as opposed to excluding them in the sensitivity analysis), the magnitude of our observed would have been even greater as those patients were more likely to be exposed to ADT.

Our study has several strengths. The KPSC health plan data enabled us to adjust for a comprehensive set of covariates, enabled long-term follow-up, and provided a large population. Moreover, the oral medications were extracted from dispensed prescriptions, ensuring that patients were indeed exposed to such medications. Unlike other studies, we were able to account for the confounding effects of antidiabetic medication use as well as other cardiovascular medications. For example, as nearly $40 \%$ of the men used antilipemics, we were able to account for this drug and other medications that were strongly related with CVD outcomes. In the SEER-Medicare studies, the higher risk of CVD might have been attributed to older study populations and their inability to account for CVD medication use, although other studies that included younger populations have also demonstrated associations of ADT with CVD (Keating et al, 2010). With the prospectively collected utilisation data, we were able to assess if history of preexisting CVD and known CVD risk factors (hypertension, diabetes, race/ethnicity, and other comorbidities) accounted for all the elevated risk of ADT on CVD. Furthermore, the time-dependent Cox proportional models allowed us to address immortal time bias. Additionally, the health plan's members' socioeconomic status, cancer incidence, and race/ethnicity reflect the general southern California population. Thus our results are generalisable to the region the health plan serves. However, the study is based in a managed care setting where patients with risk factors for CVD are closely monitored. Finally, we examined 10 individual CVD events rather than a single composite outcome by doing 10 statistical tests, which allows us to distinguish potential differential effect on specific CVD subtypes. We do not believe that the observed increased risks were simply due to chance, considering prior knowledge of the associations between lower hormone level and CVD incidences. Thus no adjustment for multiple comparison was conducted (Rothman, 1990).

Certain limitations of our study should also be considered. First, there may be residual confounding by indication. Although we adjusted for numerous potential confounders in the model and addressed missing data, we cannot rule out the possibility that some factors that may influence ADT use and the outcomes were not captured. Well-conducted randomised controlled trials are needed to verify the study results. Second, owing to data limitations, we could not examine the duration of ADT use and treated the exposure as permanent use once prescription was initiated even if they discontinued afterwards; the rationale of handling ADT exposure in this way is based on the prior study by Keating et al (2006). In that study, a sensitivity analysis was conducted comparing two definitions of ADT exposure: (1) as continuously treated for 6 months after each dose of GnRH agonist, and (2) as permanently used on GnRH agonist therapy. Similar results were obtained with the two definitions, because in some men, hypogonadism persisted for $>6$ months after discontinuing GnRH agonist therapy (Keating et al, 2006). Another limitation is that we did not distinguish intermittent and continuous ADT administration. However, a recent clinical trial comparing intermittent and continuous ADT treatment indicated an increased cumulative incidence of ischaemic events following intermittent ADT (Hershman et al, 2016). Third, disenrollment from the health plan among ADT group $v s$ the non-user group might contribute to selection bias. Fourth, we did not have BMI status for $72 \%$ of the subjects, nor smoking status for $35 \%$ of the subjects, important predictors of CVDs as these factors were not electronically available until 2006 in our electronic health records. However, in sensitivity analyses restricted to 1983 subjects with complete BMI and smoking status, the additional adjustment for these two covariate minimally changed the hazard ratio estimates (Table 4), probably because our adjustment of CVD drugs, diabetes, hypertension, statins, and antidiabetic medications have indirectly controlled for smoking and potentially other metabolomic disorders. Fifth, our study only examined one subtype of ADT, GnRH agonists; however, prior studies show that most men are treated with such agonists while $\mathrm{GnRH}$ antagonists (which were not available in the KPSC formulary) were less commonly used. Separate studies that focus on cardiovascular events following GnRH antagonist treatment are needed (Albertsen et al, 2014). Finally, we may have been underpowered to find differences for some of the rarer outcomes.

Future observational studies need to examine CVD outcomes in prostate cancer survivors who have been diagnosed in more recent years when the newer GnRH antagonist drugs were launched into the market and follow them for sufficient time to compare the long-term safety of different subtypes of ADT. Additionally, intervention studies addressing primary or secondary prevention of CVD in men with localised prostate cancer are needed.

\section{CONCLUSIONS}

In this population-based study, ADT was associated with greater risk of HF and arrhythmia and conduction disorder in men with preexisting CVD. These conditions affect patients' quality of life and morbidity and can possibly compromise survival. This study provides the basis for identifying susceptible individuals for regular cardiac check-up, including identifying subclinical signs, monitoring hypertension, diabetes, and encouraging physical activity 
and healthy dietary habits. Indeed, emerging evidence exists that recommending diet and exercise to patients receiving $\mathrm{ADT}$ for prostate cancer treatment benefits the cardiometabolic profile (Galvao et al, 2009); such efforts may indirectly help lower the risk of non-fatal CVD in men with localised prostate cancer treated with ADT.

\section{ACKNOWLEDGEMENTS}

We thank Jiaxiao Shi, $\mathrm{PhD}$ for biostatistical consultation. This study was supported by National Institutes of Health/NCI R01 CA142934 (to ALP) and Kaiser Permanente Research and Evaluation.

\section{CONFLICT OF INTEREST}

The authors declare no conflict of interest.

\section{ETHICS APPROVAL AND CONSENT TO PARTICIPATE}

The Kaiser IRB approved this study and written informed consent was waived as we were using secondary data.

\section{AUTHOR CONTRIBUTIONS}

Study concept and design, acquisition of data and drafting of the manuscript: RH, XX. Analysis and interpretation of data and critical revision of the manuscript for important intellectual content: all authors. All authors read and approved the final manuscript.

\section{REFERENCES}

Albertsen PC, Klotz L, Tombal B, Grady J, Olesen TK, Nilsson J (2014) Cardiovascular morbidity associated with gonadotropin releasing hormone agonists and an antagonist. Eur Urol 65: 565-573.

Bolla M, Collette L, Blank L, Warde P, Dubois JB, Mirimanoff R-O, Storme G, Bernier J, Kuten A, Sternberg C, Mattelaer J, Torecilla JL, Pfeffer JR, Cutajar CL, Zurlo A, Pierart M (2002) Long-term results with immediate androgen suppression and external irradiation in patients with locally advanced prostate cancer (an EORTC study): a phase III randomised trial. Lancet 360: 103-108.

Bolla M, de Reijke TM, Van Tienhoven G, Van den Bergh AC, Oddens J, Poortmans PM, Gez E, Kil P, Akdas A, Soete G, Kariakine O, van der Steen-Banasik EM, Musat E, Pierart M, Mauer ME, Collette L, Group ERO, Genito-Urinary Tract Cancer Group (2009) Duration of androgen suppression in the treatment of prostate cancer. $N$ Engl J Med 360: 2516-2527.

Bolla M, Gonzalez D, Warde P, Dubois JB, Mirimanoff RO, Storme G, Bernier J, Kuten A, Sternberg C, Gil T, Collette L, Pierart M (1997) Improved survival in patients with locally advanced prostate cancer treated with radiotherapy and goserelin. $N$ Engl J Med 337: 295-300.

Bosco C, Bosnyak Z, Malmberg A, Adolfsson J, Keating NL, Van Hemelrijck M (2015) Quantifying observational evidence for risk of fatal and nonfatal cardiovascular disease following androgen deprivation therapy for prostate cancer: a meta-analysis. Eur Urol 68: 386-396.

Burton DG, Giribaldi MG, Munoz A, Halvorsen K, Patel A, Jorda M, Perez-Stable C, Rai P (2013) Androgen deprivation-induced senescence promotes outgrowth of androgen-refractory prostate cancer cells. PLoS One 8: e68003.

Cattabiani C, Basaria S, Ceda GP, Luci M, Vignali A, Lauretani F, Valenti G, Volpi R, Maggio M (2012) Relationship between testosterone deficiency and cardiovascular risk and mortality in adult men. J Endocrinol Invest 35: 104-120.
D’Amico AV, Denham JW, Crook J, Chen MH, Goldhaber SZ, Lamb DS, Joseph D, Tai KH, Malone S, Ludgate C, Steigler A, Kantoff PW (2007) Influence of androgen suppression therapy for prostate cancer on the frequency and timing of fatal myocardial infarctions. J Clin Oncol 25: $2420-2425$.

Galvao DA, Taaffe DR, Spry N, Joseph D, Newton RU (2009) Cardiovascular and metabolic complications during androgen deprivation: exercise as a potential countermeasure. Prostate Cancer Prostatic Dis 12: 233-240.

Hak AE, Witteman JC, de Jong FH, Geerlings MI, Hofman A, Pols HA (2002) Low levels of endogenous androgens increase the risk of atherosclerosis in elderly men: the Rotterdam study. J Clin Endocrinol Metab 87: 3632-3639.

Haque R, Yood MU, Geiger AM, Kamineni A, Avila CC, Shi J, Silliman RA, Quinn VP (2011) Long-term safety of radiotherapy and breast cancer laterality in older survivors. Cancer Epidemiol Biomarkers Prev 20: 2120-2126.

Hershman DL, Unger JM, Wright JD, Ramsey S, Till C, Tangen CM, Barlow WE, Blanke C, Thompson IM, Hussain M (2016) Adverse health events following intermittent and continuous androgen deprivation in patients with metastatic prostate cancer. JAMA Oncol 2: 453-461.

Horwitz EM, Bae K, Hanks GE, Porter A, Grignon DJ, Brereton HD, Venkatesan V, Lawton CA, Rosenthal SA, Sandler HM, Shipley WU (2008) Ten-year follow-up of radiation therapy oncology group protocol 92-02: a phase III trial of the duration of elective androgen deprivation in locally advanced prostate cancer. J Clin Oncol 26: 2497-2504.

Jones RD, Nettleship JE, Kapoor D, Jones HT, Channer KS (2005) Testosterone and atherosclerosis in aging men: purported association and clinical implications. Am J Cardiovasc Drugs 5: 141-154.

Keating NL, O'Malley AJ, Freedland SJ, Smith MR (2010) Diabetes and cardiovascular disease during androgen deprivation therapy: observational study of veterans with prostate cancer. J Natl Cancer Inst 102: 39-46.

Keating NL, O'Malley AJ, Smith MR (2006) Diabetes and cardiovascular disease during androgen deprivation therapy for prostate cancer. J Clin Oncol 24: 4448-4456.

Keating NL, O'Malley AJ, Freedland SJ, Smith MR (2013) Does comorbidity influence the risk of myocardial infarction or diabetes during androgendeprivation therapy for prostate cancer? Eur Urol 64: 159-166.

Khaw KT, Dowsett M, Folkerd E, Bingham S, Wareham N, Luben R, Welch A, Day N (2007) Endogenous testosterone and mortality due to all causes, cardiovascular disease, and cancer in men: European prospective investigation into cancer in Norfolk (EPIC-Norfolk) Prospective Population Study. Circulation 116: 2694-2701.

Lubart E, Yarovoy A, Gal G, Krakover R, Leibovitz A (2015) QT interval length in elderly prostatic cancer patients on anti-testosterone treatment. Isr Med Assoc J 17: 356-359.

Martin-Merino E, Johansson S, Morris T, Garcia Rodriguez LA (2011) Androgen deprivation therapy and the risk of coronary heart disease and heart failure in patients with prostate cancer: a nested case-control study in UK primary care. Drug Saf 34: 1061-1077.

Nanda A, Chen MH, Moran BJ, Braccioforte MH, Dosoretz D, Salenius S, Katin M, Ross R, D'Amico AV (2014) Neoadjuvant hormonal therapy use and the risk of death in men with prostate cancer treated with brachytherapy who have no or at least a single risk factor for coronary artery disease. Eur Urol 65: 177-185.

Nguyen PL, Alibhai SMH, Basaria S, D’Amico AV, Kantoff PW, Keating NL, Penson DF, Rosario DJ, Tombal B, Smith MR (2015) Adverse effects of androgen deprivation therapy and strategies to mitigate them. Eur Urol 67: 825-836.

Nguyen PL, Je Y, Schutz FA, Hoffman KE, Hu JC, Parekh A, Beckman JA, Choueiri TK (2011) Association of androgen deprivation therapy with cardiovascular death in patients with prostate cancer: a meta-analysis of randomized trials. JAMA 306: 2359-2366.

O’Farrell S, Garmo H, Holmberg L, Adolfsson J, Stattin P, Van Hemelrijck M (2015) Risk and timing of cardiovascular disease after androgen-deprivation therapy in men with prostate cancer. J Clin Oncol 33: 1243-1251.

Potosky AL, Haque R, Cassidy-Bushrow AE, Yood MU, Jiang M, Tsai H-T, Luta G, Keating NL, Smith MR, Van Den Eeden SK (2014) Effectiveness of primary androgen-deprivation therapy for clinically localized prostate cancer. J Clin Oncol 32: 1324-1330.

Punnen S, Cooperberg MR, Sadetsky N, Carroll PR (2011) Androgen deprivation therapy and cardiovascular risk. J Clin Oncol 29: 3510-3516.

Rothman KJ (1990) No adjustments are needed for multiple comparisons. Epidemiology 1: 43-46.

Rubin DB (2008) Multiple Imputation for Nonresponse in Surveys. John Wiley \& Sons pp 1-26. 
Sharifi N, Gulley JL, Dahut WL (2005) Androgen deprivation therapy for prostate cancer. JAMA 294: 238-244.

Smith GD, Ben-Shlomo Y, Beswick A, Yarnell J, Lightman S,

Elwood P (2005) Cortisol, testosterone, and coronary heart disease. Circulation 112: 332-340.

Thompson I, Thrasher JB, Aus G, Burnett AL, Canby-Hagino ED, Cookson MS, D'Amico AV, Dmochowski RR, Eton DT, Forman JD (2007) Guideline for the management of clinically localized prostate cancer: 2007 update. J Urol 177: 2106-2131.

Traish AM, Saad F, Guay A (2009) The dark side of testosterone deficiency: II. Type 2 diabetes and insulin resistance. J Androl 30: 23-32.

Van Hemelrijck M, Garmo H, Holmberg L, Ingelsson E, Bratt O, Bill-Axelson A, Lambe M, Stattin P, Adolfsson J (2010) Absolute and relative risk of cardiovascular disease in men with prostate cancer: results from the Population-Based PCBaSe Sweden. J Clin Oncol 28: 3448-3456. van Noord C, Rodenburg EM, Stricker BH (2011) Invited commentary: sex-steroid hormones and QT-interval duration. Am J Epidemiol 174: 412-415.

Ziehr DR, Chen MH, Zhang D, Braccioforte MH, Moran BJ, Mahal BA, Hyatt AS, Basaria SS, Beard CJ, Beckman JA, Choueiri TK, D'Amico AV, Hoffman KE, Hu JC, Martin NE, Sweeney CJ, Trinh QD, Nguyen PL (2015) Association of androgen-deprivation therapy with excess cardiacspecific mortality in men with prostate cancer. BJU Int 116: 358-365.

This work is published under the standard license to publish agreement. After 12 months the work will become freely available and the license terms will switch to a Creative Commons AttributionNonCommercial-Share Alike 4.0 Unported License.

Supplementary Information accompanies this paper on British Journal of Cancer website (http://www.nature.com/bjc) 